\title{
DESIGN AND EVALUATION OF A Hg(II) SENSOR BASED ON THE RESPONSE OF A POLY(3,4- ETHYLENEDIOXYTHIOPHENE) MODIFIED ELECTRODE
}

\author{
M. A. DEL VALLE*, P. LLANQUILEO, F. R. DÍAZ, M. FAÚNDEZ, L. A. HERNÁNDEZ, B. GONZÁLEZ
}

Pontificia Universidad Católica de Chile, Facultad de Química, Departamento de Química Inorgánica,

Laboratorio de Electroquímica de Polímeros, Av. V. Mackenna 4860, 7820436, Macul, Santiago, Chile

\begin{abstract}
The electro-synthesis of poly(3,4-ethylenedioxythiophene), PEDOT, has been widely studied due to its different and important applications. Considering that one of the most important electrochemical characteristics of this polymer is its ability to undergo $p$-and n-doping/undoping, our research group has tested its potential usefulness for cations extraction based on the n-doping/undoping process, hitherto almost unexplored. Therefore, in a first stage, EDOT was electropolymerized on AISI 316 stainless steel, SS, and the SS|PEDOT modified electrode was then obtained. Applying the $n$-doping potential to these SS|PEDOT electrodes immersed in $\mathrm{Hg}(\mathrm{II})$ solution at physiological $\mathrm{pH}$ (PBS) it was verified that the cation was incorporated into the polymeric matrix and, depending on the area of the working electrode and removal method (n-doping/undoping), its quantitative extraction was possible. It was also found that the charge recorded during the process is proportional to $\mathrm{Hg}(\mathrm{II})$ concentration, hence the assembly is now proposed as sensor for this cation. To this end, in the current paper the amperometric response of the SS|PEDOT electrode toward $\mathrm{Hg}(\mathrm{II})$ in PBS, prepared under the optimum conditions previously established and described, was studied. First of all, it is noteworthy establishing that the response obtained with a freshly prepared SS|PEDOT electrode prior to each measurement is highly reproducible. Having this in mind, the modified electrode can be thought as a sensor that may be utilized as a disposable device. Once the electrode response was optimized, analytical parameters were established, namely linear response between $66.6 \mu \mathrm{mol} \cdot \mathrm{L}^{-1}-1.0 \mathrm{mmol} \cdot \mathrm{L}^{-1} \mathrm{Hg}(\mathrm{II}), 1 \mathrm{~s}$ response time, and quantification and detection limit 10 and $15 \mu \mathrm{mol} \cdot \mathrm{L}^{-1}$, respectively. It is possible thus to have at our disposal a suitable and inexpensive sensor that would enable quick and economical quantification of this toxic element using electrochemical methods.
\end{abstract}

Keywords: modified electrode, poly(3,4-ethylenedioxythiophene), mercury, electrochemical sensor.

\section{INTRODUCTION}

The wide range of applications that conducting polymers possess, e.g. sensors, batteries, fuel cells, photocells, light emitting diodes, etc. makes these materials one of the most studied topics at present ${ }^{1-15}$. Among these polymers polyaniline, polypyrrole, polythiophene and its derivatives stand out. Besides, PEDOT, which is obtained when 3,4-ethylenedioxythiophene (EDOT) is electro-oxidized on various substrates such as $\mathrm{Al}$, Pt, glassy carbon, etc. ${ }^{16-}$ ${ }^{21}$, occupies a prominent place. The obtained conducting polymer has been extensively characterized and one of its remarkable properties is that presents the possibility of undergoing both $p$ - and n-doping/undoping. In turn, the $p$-doping/undoping process has been thoroughly studied, while the $n$-doping/ undoping was first mentioned only in $1994{ }^{17}$ and since then, only a few publications have addressed the subject ${ }^{22}$; as a consequence, this challenge has been tackled recently and together with EDOT, the electro-polymerization of several of its analogues has been studied in order to gain a deeper understanding of the $n$-doping/undoping process and the effect of monomer structure on this property 23. 3,4-ethylenedioxythiophene, 3,4-propylenedioxythiophene, 3,4-ethylenedioxypyrrole and 3,4 propylenedioxypyrrole, thiophene and pyrrole derivatives, were electro-polymerized by potentiodynamic and potentiostatic methods on AISI 316 stainless steel electrodes, using lithium perchlorate as supporting electrolyte in acetonitrile. In all cases electrodes modified with the respective polymeric deposit were obtained. One of the most relevant features of these polymers is that their voltammetric studies revealed that all presented reversible $p$ - and $n$-doping/undoping processes. Consequently, we set out to exploit this last property, so little explored as far as the application of these materials is concerned, considering its prospective utility in the development of a device for cations extraction ${ }^{24}$. To this purpose, it was bore in mind previous results concerning the use of polypyrrole $p$-doping/undoping for arsenate ion and copper complexes extraction ${ }^{25-29}$, proving that just as $p$-doping/undoping was suitable for anions removal or extraction, so was n-doping/undoping for cations. Furthermore, in the case of arsenic a sensor was designed to determine this element in its anionic form ${ }^{30}$. $n$-doping studies revealed that during $\mathrm{Hg}$ (II) cation removal, the recorded charge was directly proportional to the metal ion concentration, hence the design and evaluation of the electrode as sensor was proposed. Although all the analogous studied showed a similar $n$-doping/ undoping process, EDOT was chosen because it was the most affordable.

Although currently different methods exist for determining mercury ions, e.g. atomic absorption spectrometry ${ }^{31,32}$, spectrofluorimetry ${ }^{33,34}$, atomic fluorescence spectrometry ${ }^{35}$, among others ${ }^{36}$, and since most of them are not only very time consuming but require costly and sophisticated instrumentation and/or expensive pre-treatment, the technique proposed in this work is quite simple and cheap. Consequently, the development of an approach that allows fast and in-situ determination of this pollutant is necessary. Electrochemical sensing devices offer a more economical solution than other analytical methods. Electrochemical techniques have the advantages of high sensitivity, excellent selectivity, low cost, and simple instrumentation and operation.

\section{EXPERIMENTAL}

All electrochemical measurements (polymerization and characterization) were performed on an AUTOLAB PGSAT 20 potentiostat, at room temperature $\left(20^{\circ} \mathrm{C}\right)$ under high purity argon atmosphere in anchor-type three-compartment electrochemical cells, using a $0.07 \mathrm{~cm}^{2}$ geometric area AISI 316 stainless steel (SS) discs as working electrode, a platinum wire coil of large geometric area as counter electrode, and $\mathrm{Ag} \mid \mathrm{AgCl}$ in tetramethylammonium chloride solution to match the potential of a saturated calomel electrode, SCE, as reference electrode ${ }^{37}$. Unless otherwise stated, all potentials quoted in the current work are referred to this electrode at room temperature.

SS|PEDOT modified electrodes were prepared by electropolymerization of the monomer on SS discs under the previously established optimal working conditions ${ }^{24}$, i.e. $0.01 \mathrm{~mol} \cdot \mathrm{L}^{-1}$ monomer, $0.1 \mathrm{~mol} \cdot \mathrm{L}^{-1}$ lithium perchlorate $(\mathrm{LiClO} 499$ $\%$, Aldrich) supporting electrolyte in acetonitrile $\left(\mathrm{CH}_{3} \mathrm{CN} 99.8 \%\right.$, Aldrich) as solvent.

All aqueous solutions were prepared using freshly deionized water from a Heal Force (Smart Series) deionizer. To test the modified electrode as $\mathrm{Hg}(\mathrm{II})$ sensor, a $0.01 \mathrm{~mol} \cdot \mathrm{L}^{-1} \mathrm{Hg}(\mathrm{II})$ solution was prepared by dissolving $0.272 \mathrm{~g}$ mercury(II) chloride in PBS pH 7.4 (physiological buffer solution) and then diluting up to $100 \mathrm{~mL}$ with the same buffer. The following aliquots of this stock solution were taken: $5,10,50,100,250,500,750,1000,1250,1500$ and 2000 $\mu \mathrm{L}$ diluted up to $15 \mathrm{~mL}$ with PBS.

To verify its voltammetric profile, cyclic voltammograms at the SS|PEDOT modified electrode were run, within the $n$-doping/undoping region, on each solution. It was established thereupon that the most suitable potential to perform amperometric and/or charge (i/t) measurements at this electrode was $-0.4 \mathrm{~V}$.

To study repeatability and reproducibility, each measurement was performed at least 5 times, using each time a freshly prepared electrode, or then, using the same sensor to measure successively the whole series of solutions.

The blank solution was prepared using lithium perchlorate (supporting electrolyte) in acetonitrile as solvent, giving a standard deviation $\left(\mathrm{S}_{0}\right)$ of $2.2 \cdot 10$ 


\section{RESULTS AND DISCUSSION}

Firstly, EDOT electro-oxidation on steel under the previously described conditions to obtain a PEDOT deposit whose $n$-doping/undoping works properly for the proposed process, was corroborated ${ }^{24}$. Figure 1 shows the voltammetric profile recorded for 50 successive voltammetric cycles under conditions established as optimum. Figure 1 reveals, on the one hand, a continuous current increase that accounts for the growth of the polymeric deposit and, on the other hand, the possibility of both $p$ - and $n$-type doping/undoping at ranges between 0 and $1 \mathrm{~V}$ and 0 and $-1 \mathrm{~V}$, respectively. In addition, the potentiostatic obtention of the polymer modified electrode at $c a .1 .4 \mathrm{~V}$ was confirmed. In such case, transients such as that in Fig. 2, highly reproducible and that allows verifying the proper obtaining of SS|PEDOT to be used as sensor, were recorded. An initial current rise is observed that drops exponentially until that, when nucleation that causes deposit growth (induction time) occurs, increases again in terms of such growth. Thus, it was confirmed that, as pointed out previously, $1.4 \mathrm{~V}$ is a suitable potential for EDOT potentiostatic electro-oxidation under the employed experimental conditions. Thereby, application of the potential for $1 \mathrm{~min}$ is enough to obtain a film of suitable thickness for further use; highly reproducible responses are obtained within the n-doping/undoping region in solution containing just supporting electrolyte (Fig. 3), which are used as "fingerprint" to check electrode preparation repeatability.

Analysis of the voltammetric response in the $n$-doping/undoping region of the SS|PEDOT electrode prepared under the optimum conditions set out herein, Fig. 3, revealed that, besides of high repeatability, reversibility of the process with respect to charge exists. So, it was precisely based on this response that the preparation of the modified electrode was optimized. It was also observed that when the measurement was accomplished in the same supporting electrolyte in which the deposit was prepared, the charge is much lower than in solutions containing $\mathrm{Hg}(\mathrm{II})$, which demonstrate the feasibility of using the SS|PEDOT device as sensor for this cation: Table 1 summarizes the charges obtained with the modified electrode under the above described experimental conditions.

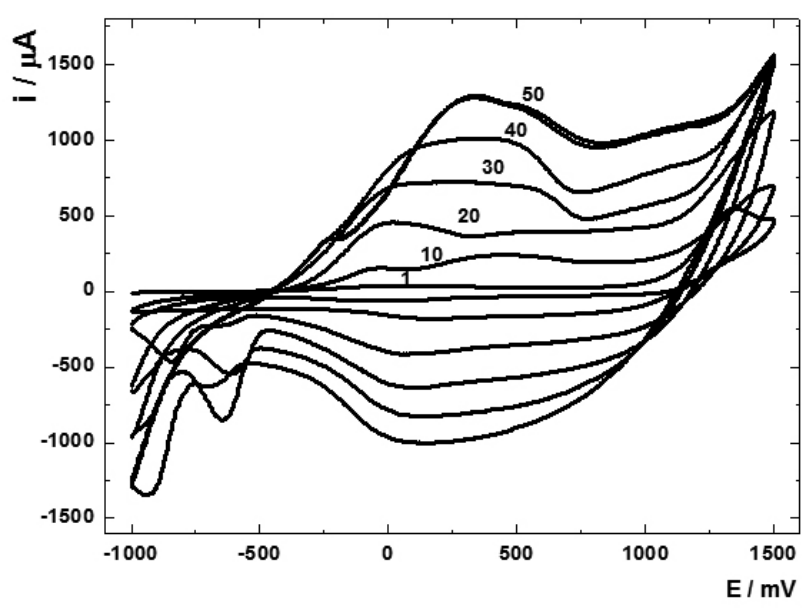

Figure 1. Voltammetric profiles recorded during the electro-oxidation on a $0.07 \mathrm{~cm}^{2} \mathrm{SS} \operatorname{disc}\left(v=50 \mathrm{mV} \cdot \mathrm{s}^{-1}\right)$ of $0.01 \mathrm{~mol} \cdot \mathrm{L}^{-1} \mathrm{EDOT}+0.1 \mathrm{~mol} \cdot \mathrm{L}^{-1} \mathrm{LiClO}_{4}$ in $\mathrm{CH}_{3} \mathrm{CN}$, by cyclic voltammetry (number of cycle indicated on the respective curve).

Table 1. Charges of $n-$ doping $\left(n-Q_{d}\right)$ and $n-$ undoping $\left(n-Q_{w}\right)$ of electrosynthesized PEDOT on SS within the respective negative $\left(\mathrm{E}_{\mathrm{cat}}\right)$ and positive $\left(\mathrm{E}_{\text {an }}\right)$ limits.

\begin{tabular}{|c|c|c|c|c|}
\hline $\mathbf{E}_{\text {cat }}(\mathbf{V})$ & $\mathbf{E}_{\text {an }}(\mathbf{V})$ & $\mathbf{n}-\mathbf{Q}_{\mathbf{d}}(\mathbf{C})$ & $\mathbf{n}-\mathbf{Q}_{\mathbf{u}}(\mathbf{C})$ & $\mathbf{n}-\mathbf{Q}_{\mathrm{d}}: \mathbf{n}-\mathbf{Q}_{\mathrm{d}}(\mathbf{C})$ \\
\hline-1.0 & 0.0 & $4.0 \cdot 10^{-4}$ & $4.0 \cdot 10^{-4}$ & 1.0 \\
\hline
\end{tabular}

The response of the SS|PEDOT electrode as $\mathrm{Hg}(\mathrm{II})$ amperometric sensor at physiological $\mathrm{pH}$ was then assayed and optimized. To this purpose, from the voltammetric profiles depicted in Fig. 3, potentiostatic transients were recorded to optimize the potential to be set for the amperometric experiment. The optimum value was $-0.4 \mathrm{~V}$ and the response time $5 \mathrm{~s}$. The recorded transient (not shown), presented an initial current rise that tends to decrease, but quickly reaches a constant value, at times never longer than $5 \mathrm{~s}$, irrespective of analyte concentration; accordingly, this time was selected to conduct current readings.

To determine the sensor useful life, analyte solutions were prepared for the construction of calibration curves. Once the modified electrode was prepared according to the conditions previously established, the doping potentiostatic perturbation was applied to each solution containing a known $\mathrm{Hg}$ (II) concentration and, between each measurement, $0 \mathrm{~V}$ undoping potential was applied for $10 \mathrm{~min}$ to a solution containing just $0.1 \mathrm{~mol} \cdot \mathrm{L}^{-1}$ supporting electrolyte.

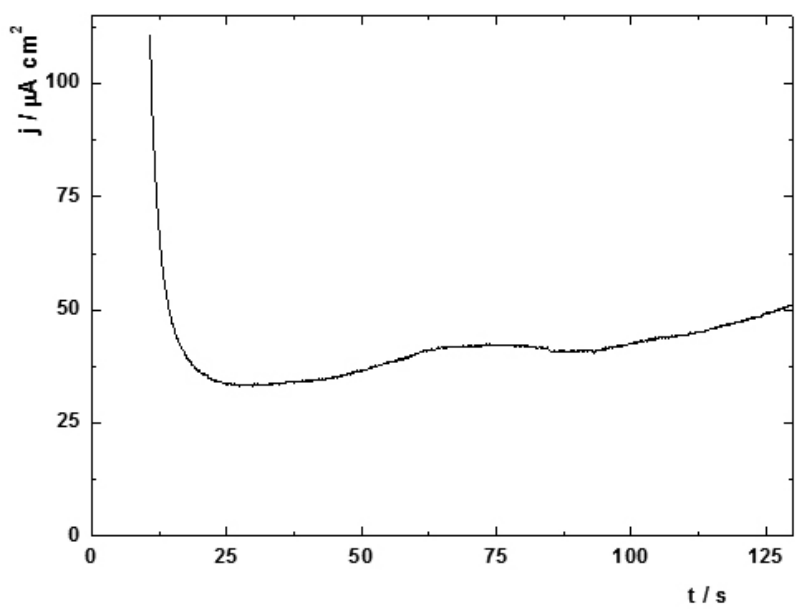

Figure 2. $\mathrm{j} / \mathrm{t}$ transient recorded during the potentiostatic EDOT electrooxidation on a $0.07 \mathrm{~cm}^{2} \mathrm{SS}$, in solution similar to that of Fig. 1 .

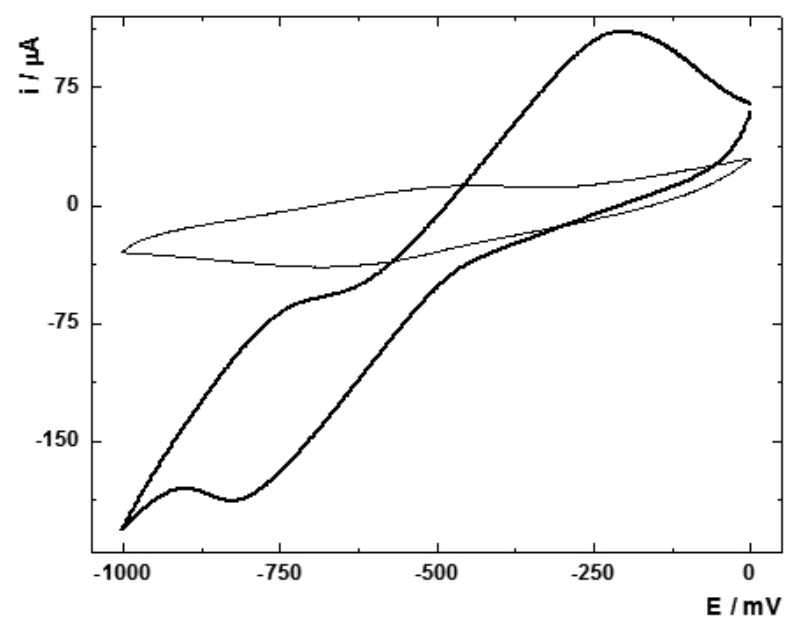

Figure 3. SSPEDOT device voltammetric response within the $n$-doping/ undoping potential range in PBS $+1 \cdot 10^{-3} \mathrm{~mol} \cdot \mathrm{L}^{-1}$ of: $\mathrm{Li}^{+}$(thin line) and $\mathrm{Hg}(\mathrm{II})$. $v=50 \mathrm{mV} \cdot \mathrm{s}^{-1}$.

The recorded transient perturbation revealed that, when the same electrode is successively utilized, the signal corresponding to the current rise decreases as $\mathrm{Hg}(\mathrm{II})$ concentration increases. This finding could be ascribed to that, even if the undoping potential is applied for 10 minutes, not all counterions have left the polymer network; therefore it might be necessary to prepare a "fresh" SSPEDOT each time a new measurement is performed, i.e. the use of the SS PEDOT electrode should be thought as a disposable device, which is not too expensive considering the low cost of the employed materials. It is noteworthy, though, that whenever a "fresh" electrode is prepared, exactly the same result is attained, so that repeatability is assured. Besides, if not used, the sensor exhibits the same response even 10 days after its preparation when the device is kept under laboratory environmental conditions. However, more time is required to set the maximum shelf life, although this is admittedly a stable polymer ${ }^{38}$.

Taking these issues into account, a "fresh" modified electrode was prepared prior to each current measurement as a function of $\mathrm{Hg}(\mathrm{II})$ concentration in order to construct a calibration curve from which the analytical parameters are set. 
The electrochemical perturbation was applied to supporting electrolyte solutions, PBS, in the absence of analyte, setting the doping potential at $-0.4 \mathrm{~V}$ during 2.5 and $10 \mathrm{~s}$. Each measurement was repeated at least 5 times and the standard deviation (s) of blank responses was calculated as well as the minimum detectable signal $\left(S_{\text {min }}\right)$, limit of detection (LOD), limit of quantification (LOQ) and linear range.

After ascertaining the optimum n-doping potential for the analytical measurement as $-0.4 \mathrm{~V}$ during $5 \mathrm{~s}$, the linear working range for $\mathrm{Hg}(\mathrm{II})$ quantification at physiological $\mathrm{pH}$ was established. For this study the set of solutions in Table 2, as described in experimental, was prepared.

As seen in Fig. 4, the calibration curve linear range was between $6.67 \cdot 10^{-6}$ and $1 \cdot 10^{-3} \mathrm{~mol} \cdot \mathrm{L}^{-1}$.

Table 2. $\mathrm{Hg}(\mathrm{II})$ stock solutions to determine the linear range from the calibration curve.

\begin{tabular}{|c|c|}
\hline stock & $\mathbf{C}_{\mathbf{H g}(\mathrm{II})}\left(\mathbf{m o l} \cdot \mathbf{L}^{-1}\right)$ \\
\hline 1 & $3.33 \cdot 10^{-6}$ \\
\hline 2 & $6.67 \cdot 10^{-6}$ \\
\hline 3 & $3.33 \cdot 10^{-5}$ \\
\hline 4 & $6.67 \cdot 10^{-5}$ \\
\hline 5 & $1.66 \cdot 10^{-4}$ \\
\hline 6 & $3.33 \cdot 10^{-4}$ \\
\hline 7 & $5.00 \cdot 10^{-4}$ \\
\hline 8 & $6.67 \cdot 10^{-4}$ \\
\hline 9 & $8.33 \cdot 10^{-4}$ \\
\hline 10 & $1.00 \cdot 10^{-3}$ \\
\hline 11 & $1.33 \cdot 10^{-3}$ \\
\hline
\end{tabular}

At concentrations below $6.67 \cdot 10^{-6} \mathrm{~mol} \cdot \mathrm{L}^{-1}$, the signal presents no current jump consistent with the rest of performed measurements, being poorly reproducible and sometimes biased by the blank. It is quite possible this fact is due to matrix effect as a result of a competition between $\mathrm{Li}(\mathrm{I})$ ion from the supporting electrolyte and $\mathrm{Hg}(\mathrm{II})$. This behavior has been ascribed to the low concentration of the latter in the medium, giving currents close, or in some cases equal, to that of the blank.

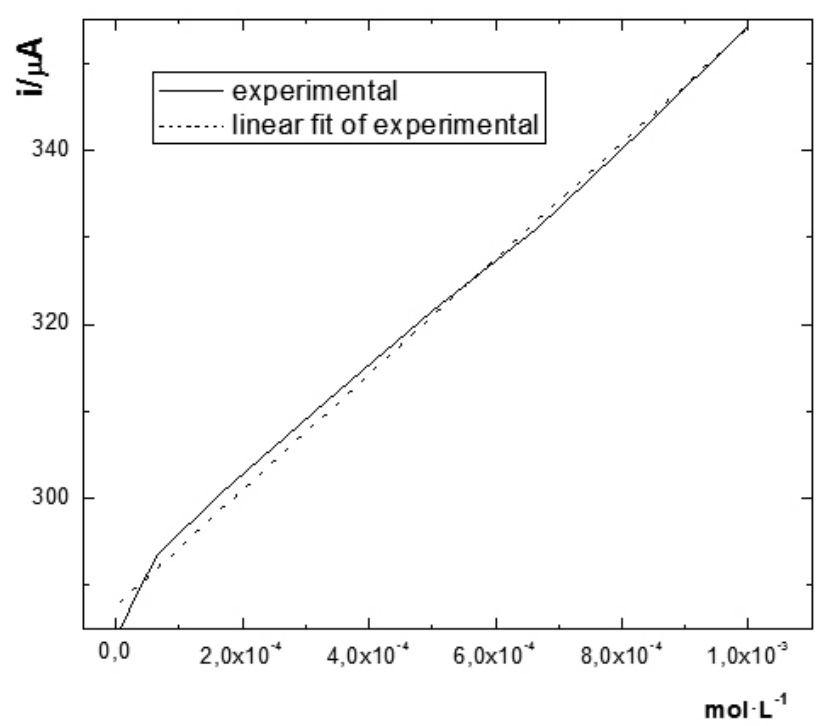

Figure 4. $\mathrm{Hg}(\mathrm{II})$ concentration $v s$ current calibration curve (at $-0.4 \mathrm{~V}$ after $5 \mathrm{~s}$ of SS|PEDOT immersion into the solution).

At concentrations higher than $1 \cdot 10^{-3} \mathrm{~mol} \cdot \mathrm{L}^{-1}$, data points deviate from linearity and a poor fit of the regression line is observed, with $\mathrm{r}^{2}$ less than 0.9996 , calculated without considering the $1.33 \cdot 10^{-3} \mathrm{~mol} \cdot \mathrm{L}^{-1}$ point.
From these results, it follows that the blank signals that produce the lowest standard deviation $\left(\mathrm{S}_{0}=2.2 \cdot 10^{-7}\right)$ is the one obtained after applying the $n$-doping potential during $5 \mathrm{~s}$. However, it is noteworthy that these data correspond to a modified electrode with $0.07 \mathrm{~cm}^{2}$ substrate area. If this area varies, so does the obtained signal value.

Analytical parameters obtained within the linear range, are summarized in Table 3 .

Table 3. Analytical parameters of SS|PEDOT modified electrode used as amperometric sensor for $\mathrm{Hg}(\mathrm{II})$ determination.

\begin{tabular}{|c|c|c|c|c|}
\hline Linear regression & $\mathbf{r}^{2}$ & $\mathbf{S}_{\mathbf{0}}$ & $\begin{array}{c}\mathbf{L O D} \\
\left(\mu \mathrm{mol} \cdot \mathbf{L}^{-1}\right)\end{array}$ & $\begin{array}{c}\mathbf{L O Q} \\
\left(\boldsymbol{\mu} \mathbf{m o l} \cdot \mathbf{L}^{-1}\right)\end{array}$ \\
\hline $\mathrm{i}=0.0665 \cdot \mathrm{C}+2.88 \cdot 10^{-4}$ & 0.99955 & $2.2 \cdot 10^{-7}$ & 10 & 15 \\
\hline
\end{tabular}

Because of the existence of the aforementioned matrix effect at concentrations less than the LOQ, the dynamic working range has been shortened, allowing working with good precision and accuracy from $3.33 \cdot 10^{-5}$ $\mathrm{mol} \cdot \mathrm{L}^{-1}$ upward.

It would be thus possible to have available for use, within the stated concentration range, a disposable, low cost $\mathrm{Hg}$ (II) sensor.

Although the dynamic range in the current work shows good analytical parameters, it would be interesting to conduct in the future a comprehensive analysis concerning selectivity, with a wide range of analytes that can be absorbed within PEDOT polymeric matrix and displays some degree of competition with $\mathrm{Hg}(\mathrm{II})$, to thereby verify whether the sensitivity can be improved for instance, using the standard addition method.

Indeed, a selectivity study is still lacking, considering that the $n$-doping/ undoping process would respond to any cation, as already observed in studies conducted in $\mathrm{LiClO}_{4}$ as supporting electrolyte. However, this can be controlled based on polymer morphology, especially, pore size. Consequently, this is the next logical step of the current study that would actually improve the sensitivity of the technique and therefore, lower the quantification and detection limits ${ }^{39}$.

\section{CONCLUSIONS}

In this work the feasibility of using the proposed electrode as a likely amperometric sensor was corroborated. Analytical performance parameters, e.g. detection and quantification limits, respectively 10 and $15 \mathrm{mmol} \cdot \mathrm{L}^{-1}$, and sensitivity 0.0665 , were found.

Among the significant findings of this study, it has been established that if a freshly prepared SS|PEDOT electrode is employed for each determination or quantification, its response was fully reproducible; consequently, the sensor can be utilized as a disposable electrode, because of the low production costs that this entails, taking a great first step forward for the rapid and economic quantification of a highly toxic ion such as $\mathrm{Hg}$ (II). In addition, a precedent for future quantification of pollutants from physiological media using electrochemical techniques is set.

\section{DEDICATION}

This work is dedicated to Dr. Luis Núñez Vergara (RIP), to whom we express our admiration and respect as a scientist and a great person.

\section{REFERENCES}

1. P. P. Zamora, M. B. Camarada, I. A. Jessop, F. R. Díaz, M. A. del Valle, L. Cattin, G. Louarn, J. C. Bernède, Int. J. Electrochem. Sci., 7(9), 8276, (2012).

2. M. A. del Valle, D. Colomer, F. R. Díaz, L. A. Hernández, M. Antilén, M. A. Gacitúa, A. Ramos, G. C. Arteaga, J. Appl. Electrochem., 42(10), 867, (2012).

3. G. C. Arteaga, M. Antilén, M. Faúndez, F. R. Díaz, F. Armijo, L. A. Hernández, A. Ramos, M. A. del Valle, Int. J. Electrochem. Sci., 8(2), 2898, (2013).

4. R. Salgado, R. del Río, M. A. del Valle, F. Armijo, J. Electroanal. Chem., 704, 130, (2013).

5. L. A. Hernández, M. A. del Valle, F. Armijo, F. R. Díaz, G. Louarn, Electrochem., 81(12), 12321, (2013).

6. M. A. del Valle, Y. Y. Chen, A. Alarcón, A. Ramos, L. A. Hernández, C. Canales, B. González, J. Chil. Chem. Soc., 58(4), 1991, (2013).

7. E. Ortega, F. Armijo, I. Jessop, M. A. del Valle, F. R. Díaz, J. Chil. Chem. Soc., 58(4), 1959, (2013). 
8. M. A. del Valle, R. Salgado, F. Armijo, Int. J. Electrochem. Sci., 9(39), 1557, (2014).

9. H. Saxena, B. Bhattacharya, N. Jadhav, V. K. Singh, S. Shukla, M. Dubey, P. K. Singh, J. Exp. Nanosci., 9, 444, (2014).

10. Z. Q. Jiang, Z.J. Jiang, J. Membrane Sci., 456, 85, (2014).

11. D. O. Flamini, M. Sango, S.B. Saidman, Corros. Sci., 81, 36, (2014).

12. A. Rogina, Appl. Surf. Sci., 296, 221, (2014).

13. G. Alfonso, M. A. del Valle, E. D. Borrego, G. M. Soto, M. E. Bodini, J. Chil. Chem. Soc. 49(2), 185, (2004).

14. F. Armijo, L. I. Canales, R. del Río, M. A. del Valle, J. Chil. Chem. Soc. 54(2), 158, (2009).

15. J. C. Bernède, J. Chil. Chem. Soc., 53(3), 1549, (2008).

16. M. A. del Valle, M. B. Camarada, F. Díaz, G. East, e-Polymers, 072, 1, (2008).

17. Q. Pei, G. Zuccarello, M. Ahlskog, O. Inganas, Polymer., 35, 1347, (1994).

18. H. J. Ahonen, J. Lukkari, J. Kankare, Macromol., 33, 6787, (2000).

19. C. Alemán, D. Curcó, J. Cassanovas, Chem. Phys. Lett., 23, 386, (2004).

20. C. Kvarnstrom, H. Neugebauer, A. Ivaska, J. Mol. Struct., 521, 271, (2000).

21. H. Gustafsson, C. Kvarnstrom, A. Ivaska, Thin Solid Films, 517, 474, (2008).

22. R. Hillman, S. J. Daisley, S. Bruckenstein, Electrochim. Acta., 53, 3763 , (2008).

23. G. C. Arteaga, M. A. del Valle, M. Antilén, F. R. Díaz, M. A. Gacitúa, P. P. Zamora, J. C. Bernède, L. Cattin, G. Louarn, Int. J. Electrochem Sci., 7, 7840, (2012).

24. G. C. Arteaga, M. A. del Valle, M. Antilén, M. Faúndez, M. A. Gacitúa, F.
R. Díaz, J. C. Bernède, L. Cattin, Int. J. Electrochem. Sci., 6, 5209, (2011). 25. M. A. del Valle, G. M. Soto, L. Guerra, J. H. Vélez, F. R. Díaz, Polym. Bull., 51, 301, (2004).

26. M. Antilén, F. J. Armijo, Appl. Polym. Sci., 113, 3619, (2009).

27. J. A. Sánchez, B. L. Rivas, S. A. Pooley, L. Basáez, E. Pereira, I. PignotPaintrand, C. Bucher, G. Royal, E. Saint-Aman, J. C. Moutet, Electrochim. Acta, 55, 4876, (2010).

28. M. Antilén, M. A. González, M. Pérez-Ponce, M. Gacitúa, M. A. del Valle, F. Armijo, R. del Río, G. Ramírez, Int. J. Electrochem. Sci., 6, 901, (2011).

29. M. Antilén, D. Guzmán, M. A. del Valle, R. del Río, M. V. Letelier, G. Lagos, M. Escudey, C. Pizarro, Int. J. Electrochem. Sci., 7, 5939, (2012).

30. M. A. del Valle, D. Colomer, F. R. Díaz, L. Hernández, M. Antilén, M. Gacitúa, A. Ramos, G. C. Arteaga, J. Appl. Electrochem., 42, 867, (2012).

31. N. Rey- Raap, A. Gallardo, Waste Manage, 32, 944, (2012).

32. Y. Zhang, S. B Adeloju, Anal. Chim. Acta, 712, 22, (2012).

33. J. Fu, H. Chen, L. Bo, C. Zhou, J. Chen, Spectrochim. Acta Part A, 77, $625,(2010)$.

34. M. Shamsipur, M. Hosseini, K. Alizadeh, A. Yari, C. Caltagirone, V. Lippolis, Anal. Chim. Acta, 533, 17, (2005).

35. L. Wu, Z. Long, L. Liu, Q. Zhou, Y. I. Lee, C. Zheng, Talanta, 94, 146, (2012).

36. H. R. Rajabi, M. Roushani, M. Shamsipur, J. Electroanal. Chem., 693, 16, (2013).

37. G. A. East, M. A. del Valle, J. Chem. Ed., 77, 97, (2000)

38. Q. Pei, G. Zuccarello, M. Ahlskogt, O. Ingan, Polymer, 35, 1347, (1994).

39. J. Wei, D. Yang, H. Chen, Y. Gao, H. Li, Sensors and Actuators B, 190, 968, (2014). 